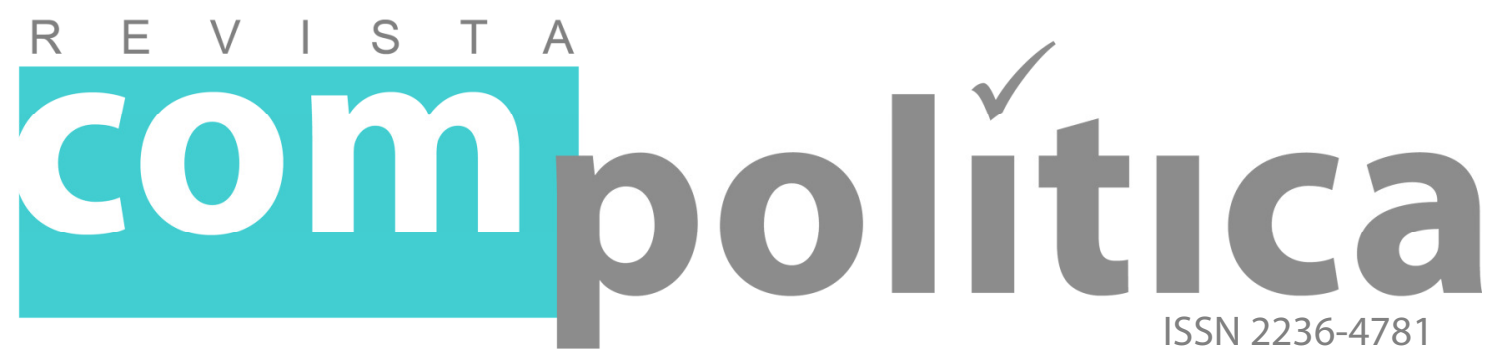

VASCONCELLOS, Fábio

Doutor em Ciência Política pelo lesp-Uerj. Mestre em Comunicação Social pela Uerj. Jornalista. <fabio.vasconcellos10@gmail.com>

\title{
Mídia e neopopulismo: uma relação de uma mútua dependência
}

RESUMO

A interação entre mídia, especialmente aquela voltada para a produção noticiosa, e o fenômeno do neopopulismo é analisada em perspectiva comparativa no livro The Media and NeoPopulism. Organizado em artigos produzidos por 15 pesquisadores sobre movimentos neopopulistas na Áustria, França, Itália, Índia, Austrália, Canadá, Estados Unidos e na região da América Latina, o trabalho oferece um panorama desse fenômeno buscando compreender em que medida ele é afetado pelo sistema de mídia na contemporaneidade. Ao refletir em torno da importância dos meios noticiosos no surgimento do neopopulismo, o estudo encara essa relação como sendo "em duas vias", uma vez que as organizações midiáticas exploram os movimentos neopopulista, mas, por outro lado, também são alvo das estratégias de comunicação formuladas por eles.

Palavras-chave: mídia; neopopulismo; comunicação política.

\section{ABSTRACT}

The interaction between media, especially the news media, and the phenomenon of neopopulism is the subject of a comparative analysis in The Media and Neo-Populism: A Contemporary Comparative Analysis. This book, organized in papers written by 15 researches about neo-populist movements in Austria, France, Italy, Australia, India, Canada, the United States, and the Latin American region, gives an overview of the phenomenon and tries to understand in which way it is affected currently by de media system. Br reflecting on the importance of the news media in the emergence of neo-populism, the research sees it as a twoway relationship, as the media organizations exploit neo-populist movements, at the same time news media are target of the communication strategies formulated by these movements.

Keywords: media; neo-populism; political communication 


\section{Mídia e neopopulismo: uma relação de uma mútua dependência}

\section{[Media and neo-populism: a two-way relationship]}

VASCONCELLOS, Fábio

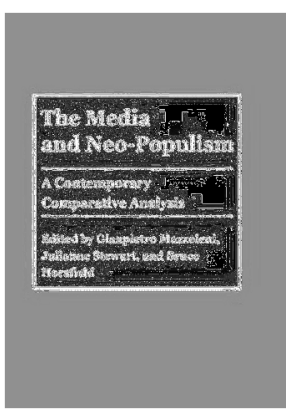

resenha de

MAZZOLENI, Gianpietro; STEWART, Julianne; HORSFIELD, Bruce (org.). The media and neopopulism: a contemporary comparative analysis. Califórnia (EEUU): Preager, 2003. 272 pp.

A depender da perspectiva analítica, a operacionalização do conceito de populismo pode assumir percursos distintos, com resultados muitas vezes ambíguos ou dotados de uma considerável imprecisão. A título de exemplo: se por populismo entendemos as ações políticas voltadas ao desejo popular, não parece haver problema imediato. Anunciar medidas com a intenção de baixar índices de desigualdade de renda, quando esta é uma questão central segundo a percepção pública, está de acordo com o que se espera da relação entre governante e eleitor. Governos são escolhidos para levarem adiante projetos ou linha ideológica com os quais estão comprometidos, e os eleitores assim esperam que aconteça.

Essa concepção, muito focada numa relação de troca de interesses entre representante e representado, deixa de lado avaliações qualitativas sobre o comportamento dos agentes. É um tipo de concepção que compreende a busca por aprovação e legitimidade pública como algo inerente à prática política numa democracia representativa. Nessa matriz, a ideia de popular emerge e não apresenta uma relação semântica com populismo. Uma perspectiva clássica dos estudos da Ciência Política sobre esse conceito, no entanto, compreende que popular transforma-se em populismo segundo os elementos que adornam os comportamentos políticos. Nesse caso, comportamentos que reforçam nesses atores a sua 
estratégia de fazer uma conexão com a percepção pública, utilizando-se de meios heterodoxos, isto é, que fogem dos canais tradicionais de identificação e resposta às demandas numa democracia.

Esses elementos heterodoxos estariam presentes não somente na escolha de determinadas agendas políticas, como na maneira pela qual os líderes arregimentam o apoio das ruas com o intuito de legitimar as suas ações. O uso de uma retórica com forte apelo ao imaginário popular, numa comunicação que busca uma identificação direta com o sentimento e os desejos do "povo", simplificando sua heterogeneidade social e política, seria a sua face mais visível. Por essa dimensão, o político populista defende proposições que contrariariam certa racionalidade político-administrativa, valores e comportamentos esperados de atores políticos numa democracia representativa, isto é, com todo o arcabouço teórico que fundamenta a visão institucionalista ${ }^{1}$.

É dessa concepção, portanto, que extraímos a conhecida ideia de que o populista é quase sempre um político desonesto, enganador, porque o seu objetivo é meramente o de mobilizar apoio a seu projeto político. Essa compreensão, como é fácil notar, apresenta também inúmeros problemas práticos. Classificar ações como populistas pelo simples uso de retóricas que apelam ao imaginário popular parece pouco compreensível, especialmente num ambiente contemporâneo no qual os atores da cena política incorporaram elementos da gramática da comunicação de massa como meio de contato e representação. O reverso desse tipo de ação seria o confinamento da política, aspecto que, definitivamente, não é da natureza da própria política.

Por outro lado, a visão institucionalista, que compreende o populismo segundo a adoção de determinadas agendas políticas, apresenta também imperfeições. Aqui a questão é fácil de contra argumentar. Definir políticas "boas" ou "ruins" como eixo analítico do populismo é propor desde o início um enquadramento dessas políticas. Enquadramentos amparados em determinadas perspectivas sobre a democracia, ainda que essas perspectivas, muitas delas de natureza liberal, desconsiderem demandas locais ou a sub-representação do acesso dos diversos grupos sociais à Fazenda Pública.

Nesse ponto, Laclau (2005) argumenta que a oposição entre a visão institucionalista liberal e o populismo sugere uma avaliação negativa

\footnotetext{
"O raciocínio institucionalista liberal é o de que os líderes populistas buscam suplantar as instituições democráticas, enfraquecendo o parlamento, os partidos políticos e mesmo instituições sociais como a Igreja e a imprensa. Dessa forma, essas lideranças seriam altamente nocivas à democracia, uma vez que estimulariam na população sentimentos avessos a uma verdadeira cultura cívica e de respeito às regras do jogo constitucional" (COUTINHO, 2006, p.120-121).
} 
do segundo termo sem considerar que este é filho do fracasso da via institucional em dar respostas às legítimas demandas populares. Em outras palavras, o populismo, segundo essa interpretação, seria também uma forma da ação política capaz de promover mudanças no status quo. Diante de tais dificuldades metodológicas, Laclau lista aspectos que precisariam ser levados em conta para não cairmos na armadilha de analisarmos populismo em razão da qualidade a priori que atribuirmos ao conceito. Para ele, populismo deveria ser entendido como:

a) uma forma, mais do que um conteúdo; uma lógica, um tipo de discurso e de articulação hegemônica; b) para a sua compreensão, contudo, o conteúdo do fenômeno não pode ser definido a priori sem considerar o contexto; c) para compreender este fenômeno político, não deveríamos fazer um uso a priori de conteúdos normativos ou axiológicos em termos de "bom ou mau".

A partir dessas indicações, Rincón e Magrini (2010) consideram que há basicamente duas formas de compreendermos o populismo: uma essencialista, e outra não essencialista. Para a primeira:

a) o populismo seria um conteúdo; b) estaria no âmbito do dever ser; c) é historicamente localizado (1930-1950); d) e é um fenômeno latino-americano/terceiro mundista.

A concepção não essencialista, por outro lado, caracterizaria o populismo como:

a) uma forma; b) no âmbito do ser; c) um fenômeno que não se reduz a um período específico no tempo; d) não é definido segundo uma especificidade espacial.

A concepção não essencialista permite uma análise do populismo segundo a lógica dos contextos locais e, fundamentalmente, a partir da sua forma, não exatamente da qualidade de um conteúdo antecipadamente definido. Embora essa seja uma concepção razoável, especialmente no contexto latino-americano, ela não resolve um problema de fundo: quais conteúdos do discurso político assegurariam uma compreensão clara sobre comportamentos populistas e não populistas, sem que caíssemos novamente numa visão institucionalista desse conceito, isto é, de uma preconcepção moral do termo? Agrega-se a essa questão um segundo ponto igualmente movediço, que diz respeito à predileção da política à visibilidade pública, característica sem a qual teria enorme dificuldade de sobrevivência nos dias atuais. Ou seja, seria 
hegemônico o ator político que recusa atender às expectativas públicas?

Apesar desses temas controversos, um ponto parece unir as dimensões essencialista e não essencialista sobre o estudo do populismo, qual seja, a análise do comportamento discursivo dos atores políticos. Contudo, elas se diferenciam nos seus achados de forma substantiva. A problematização do populismo na percepção não essencialista teria mais a ver com o estudo dos comportamentos políticos que buscam uma hegemonia, do que necessariamente a identificação negativa a priori do próprio termo. Com maior ou menor grau, a maioria dos estudos clássicos no campo da Ciência Política, por exemplo, ressaltam quase sempre o aspecto discursivo na caracterização dos líderes populistas, mas essa caracterização atende mais ao objetivo de apontar as consequências danosas da sua retórica para o funcionamento da democracia representativa e suas instituições. É o tipo de abordagem, portanto, que não elimina, mas restringe a discussão sobre as razões da eficácia mobilizadora do chamado discurso populista.

No ambiente contemporâneo, inúmeras perguntas corroborariam o peso da dimensão comunicacional do chamado neopopulismo, análise feita muito além da mera identificação do conteúdo dos discursos. Por exemplo, qual o impacto da comunicação num ambiente de democracia de público, para lembrar Manin (1995), no qual o sistema de mídia de massa ainda exerce papel fundamental na construção de imagens sobre o campo político? Essa relação joga também papel decisivo na constituição do populismo contemporâneo ou ele é dependente apenas de certa habilidade de comunicação dos líderes político, como fazem crer os estudos clássicos sobre esse fenômeno?

É nesse contexto que a obra The Media and Neo-Populism: A Contemporary Comparative Analysis, estudo organizado por Gianpietro Mazzoleni, Julianne Stewart e Bruce Horsfield, oferece interpretações bastante interessantes sobre esse fenômeno. Na obra, os autores aprofundam a discussão sobre populismo contemporâneo ao analisar o sucesso eleitoral de movimentos, partidos e líderes considerados populistas. Para isso, partem de hipótese geral de que a constituição do assim chamado neopopulismo não estaria presente apenas no tipo de política, nem somente na maneira pela qual os líderes políticos se expressam publicamente, mas fundamentalmente em como o sistema de mídia se relaciona com o campo político.

Há, nesse ponto, uma questão de suma importância na visão dos autores. O fator mídia teria um papel indiscutível no fenômeno do neopopulismo, seja porque o instrumentaliza, seja porque também é instrumentalizado por ele. Esse é o ponto louvável do estudo, porque procura discutir a mídia, sobretudo a produção noticiosa do jornalismo político e sua relação com o populismo. 
Mazzoleni et al. não consideram a mídia o único fator responsável pela emergência do neopopulismo, nem o fator determinante. 0 neopopulismo estaria associado a outras instituições e questões estruturais. Entre esses fatores, citam a natureza do sistema político e as especificidades sociais e culturais da política em cada país. Nesse sentido, a importância da mídia no surgimento do neopopulismo está mais diretamente relacionada ao fato de que ela não pode simplesmente ignorar o que pode ser interessante do ponto de vista noticioso, entre eles os políticos que desafiam a ordem, com suas linguagens abrasivas, protestos públicos e questões com alto grau de emoção. A questão é como e em que magnitude ela dá vazão a esses apelos.

A questão é que a mídia, por outro lado, é também alvo das estratégias de comunicação formuladas pelos movimentos neopopulistas, com o intuito de ganhar valor notícia. Como a mídia precisa cotidianamente de histórias, um recurso comumente usado pelos neopopulistas é a força das imagens que determinados movimentos podem produzir, como forma de conquistar espaço nos meios de comunicação. Há, portanto, uma mútua dependência. A mídia precisa de histórias, de preferência dramáticas, e os movimentos precisam tornar públicas as suas reivindicações como forma de dar suporte a elas.

\section{Notas sobre os capítulos}

The Media and Neo-Populism está organizado em artigos produzidos por 15 pesquisadores sobre movimentos neopopulistas na Áustria, França, Itália, Índia, Austrália, Canadá, Estados Unidos e na região da América Latina. De certo modo, os trabalhos oferecem um panorama desse fenômeno alinhado com a compreensão não essencialista do populismo. Ou seja, de como esse fenômeno pode se constituir de diversas maneiras nas democracias, embora mantenha uma característica geral, a formulação por lideranças que "se dirigem ao povo e falam para o povo, ressaltando que a legitimidade política reside em razão do povo" (p. 4).

Apesar da visão do populismo adotada pelos autores dialogar e muito com a concepção institucionalista, o foco central do estudo é discutir esse fenômeno mais a partir da dimensão comunicacional do que exatamente das suas consequências para a vida institucional das democracias. Nesse termo, Mazzoleni et al. argumentam que os movimentos populistas clássicos propunham uma radical transformação socioeconômica e sociocultural do status quo. Muitas vezes o seu radicalismo se misturava com o autoritarismo, rejeitando o debate participativo, o pluralismo, a tolerância com relação a discordâncias em processos decisórios e o compromisso com interesses conflitantes. O populismo contemporâneo, contudo, se 
distinguiria dos movimentos da direita fascista europeia, porque seus líderesse veem mais como democratas, que expressam queixas e opiniões populares que são sistematicamente ignoradas pelos governos, partidos e pelo mainstream da mídia.

Esse é um ponto chave da obra, que busca responder não o que é exatamente $o$ populismo segundo os efeitos maléficos à sobrevivência das instituições clássicas da democracia, mas em que medida esse fenômeno é afetado pelo sistema de mídia na contemporaneidade. Para isso, os autores partem de três hipóteses que seriam constituintes e legitimadoras do neopopulismo: 1) o processo de enquadramento do mundo político, fruto da atividade de produção noticiosa da mídia; 2) a interpelação entre sistema de mídia e sistema político e, finalmente; 3) as estratégias que os movimentos neopopulistas adotam para conseguir fazer com que suas mensagens passem pelo bloqueio noticioso da mídia.

No primeiro capítulo do livro, Fritz Plasser e Peter A. Ulcram abordam o fenômeno da direita na Áustria, mais especificamente do Partido da Liberdade Austríaca (FPÖ, sigla em inglês). Os autores relacionam o crescimento do apoio ao FPÖ a fatores estruturais, considerados como pré-condições do populismo, entre eles a dissolução das ideias que produziram o alinhamento social e político dos eleitores com os partidos tradicionais do país e, concomitantemente, a ativação de um sentimento latente relativo à rejeição aos partidos e instituições. Nesse cenário, o FPÖ foi hábil ao adotar estratégias de comunicação focadas na denúncia dos escândalos, em críticas à política de imigração ou do aumento da criminalidade, temas que faziam também parte da agenda da mídia.

Essa estratégia resultou numa maior atenção da própria imprensa local às falas dos representantes do FPÖ. Plasser e Ulcram concluem que a mídia forneceu uma permanente ressonância aos objetivos neopopulistas, porque o negativismo, associado à emocionalidade das falas do FPÖ, atendeu a um valor chave de noticiabilidade: notícia ruim é notícia boa. Os autores dedicam um bom espaço à análise da produção noticiosa na Áustria, durante a ascensão do FPÖ. Algumas conclusões gerais da mídia e que podemos encontrar em diversos países: 1) tendência ao personalismo; 2) foco na discussão de táticas e estratégias eleitorais em substituição à análise dos temas políticos; 3) forte negativismo na abordagem sobre política; 4) foco na dramatização e no suspense, e uso excessivo de pesquisas de opinião eleitoral e do enquadramento "corrida de cavalos".

A partir da mesma dimensão analítica, Guy Birenbaum e Marina Villa discutem o neopopulismo na França, mais especificamente o sucesso eleitoral da Frente Nacional (FN), liderada por Jean-Marie Le Pen. Embora ele tenha utilizado o cenário negativo construído pela mídia sobre a política do país para conquistar espaço na imprensa, os autores concluem que houve mudanças de comportamento na 
relação da própria mídia com relação a La Pen. Esse seria um indicativo interessante de que a imprensa não apresenta um comportamento receptivo ou mesmo reativo imediato, mas segundo uma lógica crescente até uma estabilização.

Num primeiro momento, a mídia francesa tendeu a atacar ou mesmo tratar com descrédito as posições políticas de Le Pen, considerado naquele momento muito associado ao fascismo europeu. Essa primeira fase foi seguida de um aumento da atenção dada pela mídia ao FN e seus líderes, em razão das entrevistas, falas e declarações com potencial de virar notícia. A terceira fase foi de uma crescente atenção às performances do $\mathrm{FN}$, reduzindo substancialmente $\mathrm{O}$ espaço para outras lideranças de partidos rivais. Nessa fase, as qualidades oratórias de Le Pen passam a ser o foco de atenção da imprensa. A quarta fase seria caracterizada como uma abordagem mais equilibrada das lideranças políticas. Nessa etapa, Le Pen tem o seu espaço reduzido, mas não suprimido.

Em seu capítulo, Roberto Biorcio, por sua vez, argumenta que a relação da mídia com o partido Liga do Norte, na Itália, esteve influenciada por fatores do sistema político daquele país. Biorcio identifica quatro cenários distintos no tipo de relação estabelecida entre o sistema de mídia e o sistema político que afetaram a emergência da Liga do Norte. Num primeiro momento, como um sistema incapaz de assumir pontos de vista críticos com relação ao status quo, isto é, ao sistema partidário tradicional. o segundo momento foi de uma relativa atenção à Liga do Norte. As falas dos seus representantes passaram de algum modo a serem usadas como instrumento de interpretação da condição política e social do país.

A terceira fase no cenário italiano foi seguida de uma profunda crise do sistema político, que permitiu de maneira mais eficaz uma abertura de críticas ao próprio sistema e, consequentemente, de um maior espaço aos representantes da Liga do Norte que souberam utilizar o cenário para atacar o sistema. A quarta e última fase, já com a Liga do Norte ocupando um expressivo espaço na política italiana, foi de denúncia e crítica aos perigos do neopopulismo. Essa última etapa caracterizou-se como um rearranjo entre os sistemas de mídia e político, no sentido de reduzir os espaços aos novos partidos.

Outro trabalho igualmente interessante é apresentado no capítulo desenvolvido por John McGuire e Geoffrey Reeves, que abordam a ascensão do partido Janata Bharatiya (BJP, sigla em inglês) na Índia. Os autores discutem como questões culturais locais afetaram o próprio sistema político e sua relação com o sistema de mídia, permitindo uma maior abertura ao BJP. Bruce Horsfield e Julianne Stewart, por sua vez, analisam o sucesso eleitoral da líder populista Pauline Hanson, na Austrália, também recorrendo à abordagem histórica, isto é, seguido de fases de uma maior e uma menor aproximação entre a mídia local e Hanson. Conhecida por seus ideais 
raciais e contra o multiculturalismo, a líder populista conseguiu despertar a atenção da mídia local depois que passou a ganhar votos, principalmente de eleitores oriundos do meio rural australiano e que estavam descontentes com o desempenho dos partidos tradicionais.

Na América do Norte, Richard W. Jenkins discute a relação entre o processo de produção noticiosa da mídia e o crescimento do partido reformista no Canadá. Como os demais autores, Jenkins vê nessa relação fatores constituintes e legitimadores do crescimento do partido reformista canadense. Jonathan Raurence, por sua vez, analisa a ascensão de Ross Perot na campanha presidencial americana, sobretudo a sua habilidade em se apresentar em programas televisivos, identificados por um excesso no uso do infoentretenimento. A estratégia de Perot permitiu que a sua imagem se popularizasse e chegasse ao cidadão comum americano.

O peso da cultura popular na mídia, especialmente a televisiva, é analisado por Silvio Waisbord ao discutir o populismo na América Latina. $O$ autor defende que o neopopulismo não pode ser compreendido apenas como fenômeno político, mas, sobretudo, como fenômeno do ambiente de comunicação predominante em muitos países da região latino-americana. Em outros termos, o que o político populista fala não deveria ser interpretado tão somente como a expressão de um sentimento antipartido, uma fala voltada estritamente para o sentimento popular, com referências nacionalistas, entre outros, mas como resultado também de uma cultura política contemporânea. Nesse cenário, a saturação de imagens nutre, glorifica e reforça o discurso populista, porque se caracteriza por uma comunicação personalista, cujas qualidades e emoções pessoais ganham enorme importância.

Para Waisbord, a programação televisiva latino-americana centra continuamente na imagem de celebridade, de pessoas populares, com suas sensibilidades e angústias. Esse meio de comunicação torna-se, em última análise, um meio populista e reforça a sua forma de comunicação como meio através do qual as narrativas políticas devem dedicar atenção. Desse modo, Waisbord ressalta: "quando a cultura popular torna-se predominante, toda a política torna-se necessariamente populista, não importa o talento ou a inclinação política dos líderes no que diz respeito à utilização de um discurso publicamente centrado no povo" (p. 214). Em outros termos, enquanto o populismo clássico se esforçava para articular uma imagem de uma população continuamente ignorada pelas elites, seja do ponto de vista social ou econômico, o neopopulismo estaria inserido numa vida pública dominada por uma mídia populista, e essa seria a principal razão da sua emergência nos dias atuais.

\section{O neopopulismo, segundo a lógica midiática}


Os estudos apresentados em The Media and Neo-Populism levam os organizadores do livro a algumas conclusões sobre o fenômeno do neopopulismo, que Gianpietro Mazzoleni, Julianne Stewart e Bruce Horsfield entendem como aspectos comuns aos países incluídos na pesquisa. Esses aspectos poderiam ser organizados a partir da caracterização do modelo de comunicação política, compreendido segundo dois grupos inter-relacionados. O primeiro diz respeito ao comportamento da comunicação política adotado pelos líderes considerados populistas, e o segundo ao comportamento da mídia, sobretudo o jornalismo político, ao retratar a realidade política do país e, pela via institucional, na maneira pela qual ela se associa ou não ao sistema político.

Com relação ao estilo de comunicação política, os autores argumentam que o neopopulismo é resultado da participação de uma liderança carismática e fortemente personalista, imediatamente identificada por sua alta visibilidade e ideias controversas. Esse potencial de comunicação seria fruto da sua habilidade para falar em público e, em alguns casos, das qualidades pessoais associadas à sua midiagenia, que eles exploram com a finalidade de ganhar popularidade e a atenção da mídia. O conteúdo das falas dos neopopulistas, por outro lado, costuma ser recheado de emoção, frases de efeito e uma linguagem em estilo tabloide, isto é, de fácil compreensão popular. Essas características resultariam quase sempre em um radicalismo verbal e na utilização de símbolos políticos como ferramenta de marketing político.

Outra característica do estilo de comunicação das lideranças neopopulistas é a ação política voltada quase sempre para uma questão central. Desse modo, eles tendem a se concentrar em uma ou poucas questões controversas, cuja percepção é mais simples, como o xenofobismo, o nacionalismo e a corrupção. Para Mazzoleni et al., isso explicaria em parte a simplicidade das mensagens dos neopopulistas e sua forte capacidade de difusão entre os eleitores. Seu objetivo é atingir a percepção pública de que os problemas que os neopopulistas apresentam são os mais importantes da sociedade.

A análise do comportamento da mídia, como segundo ponto central discutido no livro, é de fundamental importância para compreender, segundo os autores, o fenômeno do neopopulismo. O seu nascimento e propagação seriam dependentes do fator mídia, qual seja, do tipo de mídia presente em cada democracia, aqui compreendido por vários subtemas, como a predominância ou não do tabloidismo, o grau de competitividade e o tipo de relação estabelecida pelo sistema de mídia com o sistema político.

Com relação ao primeiro fator, os autores apontam a existência de dois tipos de atividade noticiosa que refletem diferentes graus de integração da indústria da informação com a cultura doméstica e o clima político: a mídia de elite e a mídia de tabloide. A primeira 
tenderia a ser mais alinhada com o status quo, nesse sentido dando mais suporte ao mainstream dos partidos políticos. Ela recorreria mais a apelos imparciais, para ser vista como uma instituição justa e responsável. A mídia de elite serie menos refém dos índices de audiência e também menos aberta aos apelos populistas.

Por outro lado, a mídia popular - como o rádio, os tabloides, os programas de TV que focam o infoentretenimento - é muito mais simpática a cobrir os movimentos neopopulistas, a focar nos traços pessoais dos atores políticos, nos valores do entretenimento, nos detalhes do conflito, mais em fofocas do que em análises. Para os autores, esse tipo de mídia é mais sensível aos índices de audiência que precisa manter e, nesse sentido, está mais aberta aos apelos populistas. Portanto, a mídia tabloide tenderia a encorajar mais o discurso populista do que a mídia de elite, mais inclinada a dar suporte ao mainstream político.

Mas os autores tornam esse argumento um pouco mais complexo ao tratarem as empresas de mídia também como atores políticos. Com isso, defendem que a mídia não é mobilizada apenas por questões profissionais, isto é, em razão de uma suposta avaliação noticiosa dos acontecimentos, mas também pelos interesses de uma elite nacional ou regional. "Se o novo movimento político que a mídia ajuda a legitimar desafiar o establishment, a mídia pode empregar o seu poderoso arsenal discursivo para neutralizar essa ameaça" (p. 7). Com esses dois elementos, a variável comercial e a variável política, o estudo reconhece que a realidade política e a estrutura da mídia têm relação com o grau de integração da mídia com o sistema político.

Este é um ponto bastante aceito nos estudos recentes sobre sistema político e midiático. Mesmo quando há uma maior integração e simbiose com a política existente, as inclinações da mídia variam significativamente de um país para o outro, podendo ser de suporte ou de hostilidade. Ou seja, certos enquadramentos ou posicionamentos contra ou a favor das notícias neopopulistas resultam numa posição ideológica, de natureza política. 0 tratamento das notícias neopopulistas pode ser um caso exemplar de resposta da mídia a determinada estrutura política, tanto quanto uma pressão contingente do próprio sistema político.

Nesse sentido, num contexto onde a política governamental "controla" o sistema midiático, e a cobertura dos partidos políticos é uma atividade comum, os interesses políticos tanto da mídia quanto da elite política estão mais alinhados. Assim, a autoconsciência profissional da mídia é mais fraca, produzindo um jornalismo afetado por determinado viés político. As coberturas negativas com enquadramentos hostis no início do neopopulismo contra o tradicional establishment político podem ser vistas como cálculo de 
reação e defesa da ordem existente, isto é, de uma ação mais sacerdotal da mídia em relação ao sistema político.

Portanto, Mazzoleni et al. entendem que o fator mídia contribui para a insurgência de movimentos neopopulistas. Contudo, o grau de integração entre o sistema de mídia e o sistema político afeta o tipo de cobertura realizado pela mídia. As organizações midiáticas podem mudar de comportamento, e refletir nos valores notícia os pontos de vista dessa elite político-midiática, tendendo a adotar um ponto de vista da lei e da ordem, e a utilizar esses valores como forma de defender o status quo quando é atacado por forças anti-establishment ou grupos de protesto populares.

Esse é o cenário no qual a mídia recorre a uma relação sacerdotal com a classe política, ignorando sistematicamente os valores dos eventos populares, suas ações e mensagens. "A legitimação pela mídia do movimento neopopulista pode ser acompanhada também de uma demonização, isto é, um tipo de cobertura alimentada pelo que a mídia defende como modelo estrutural de estabilidade política, que é vital para o seu negócio comercial e político" (p. 236).

\section{As fases do neopopulismo}

The Media and Neo-Populism oferece elementos interessantes sobre o populismo contemporâneo e que dizem respeito às fases do surgimento e declínio desse fenômeno. Esta talvez seja uma das maiores contribuições do livro. Segundo os autores, três padrões de movimentos populistas podem ser identificados nas democracias analisadas. Um rápido crescimento e rápido declínio (caso de Pauline Hanson's One Nation na Autrália, Manning's Reform Party no Canadá e Ross Perot's Reform Party nos Estados Unidos); uma lenta explanação e consolidação como partido de oposição (Le Pen's Front National na França), e uma gradual difusão e eventual conquista de cargos no governo (Haider's FPÖ na Áustria e Bossi's Lega Nort na Itália).

Dessa conjuntura, Mazzoleni et al. concluem que a maneira como a mídia trata da realidade política - seus conflitos e controvérsias políticas - subsidia a hipótese dos ciclos da vida política e midiática, e ajuda a compreender como os movimentos neopopulistas se afirmam nas democracias contemporâneas. A primeira grande fase (The Ground-Laying Phase) é caracterizada por um forte descontentamento social e político no país. A mídia, ao sustentar uma cobertura negativa e dramática da situação, indiretamente incentiva um sentimento psicológico de insegurança na sociedade, difundindo um senso geral de mal-estar e de tensão social, ou seja, um gatilho para o sentimento de anti-establishment, próreforma e de defecção política. 
Desse modo, a mídia tem uma grande contribuição por criar um clima político que engendra o discurso neopopulista e o sentimento de que a sociedade deve facilitar o nascimento de movimentos e organizações neopopulistas. Para os autores, tanto a mídia tabloide quanto a mídia de elite contribuem para a difusão do discurso neopopulista, especialmente pelo tom amplamente negativo das coberturas. O clima de cinismo e descontentamento, que a mídia de elite tende a adotar, contribui porque serve como apelo para o nascimento de partidos neopopulistas, que adotam discursos de grande mobilização popular e destinados a mudar o status quo.

A segunda grande fase (The Insurgent Phase) constitui a afirmação do neopopulismo como canal de atendimento de demandas. Essa fase caracterizada pela atenção da mídia aos movimentos políticos nascentes. $O$ valor notícia costuma ser os eventos nos quais os líderes carismáticos costumam ser atraentes, especialmente em função do seu engajamento, extremismo verbal e fortes ataques às políticas dos governos e aos partidos. Esses valores notícias estão intrinsecamente ligados aos objetivos editoriais de audiência e são vistos pela mídia com certa simpatia. A fase da insurgência dos movimentos neopopulistas assegura uma maciça publicidade que aos poucos familiariza o público com a retórica neopopulista.

Nessa fase, a extensão com que a organização midiática explora os movimentos neopopulistas tende a se relacionar com as questões comerciais das empresas de comunicação. Portanto, é na fase da insurgência que as diferenças entre a mídia de massa e a mídia de elite tendem a se atenuar. Em outras palavras, embora a elite da mídia esteja ligada aos partidos tradicionais e defenda os seus pontos de vista, ela pode perceber que corre risco de perder audiência, ampliando desse modo o espaço dos novos movimentos.

A terceira fase do neopopulismo (The established phase) é caracterizada pela ascensão desses movimentos, com legitimidade pública na cena política. Nessa fase, o volume de atenção da mídia a esses movimentos tende a encolher, produzindo novas dinâmicas de comunicação. Os líderes populistas encontram maior dificuldade para manter o nível de atenção da mídia. Por outro lado, o dia a dia da agenda política os obriga a se moverem para assuntos que não são mais tão excepcionais, nem sensacionais, e sua linguagem radical perde força de escandalizar. A atitude da mídia com relação aos neopopulistas pode variar de uma relação de hostil à amistosa.

A quarta e última fase do neopopulismo (The decline phase) é caracterizada pelo declínio do espaço que a mídia dedica a esses partidos e movimentos. No estudo comparativo, no entanto, os autores não encontraram essa característica em todos os países analisados. A conduta da mídia pode variar fortemente entre os países, dependendo do grau de aceitação dos movimentos e partidos neopopulistas nas fases anteriores. A atenção da mídia pode ser por 
conta da própria queda de popularidade de uma liderança populista ou mesmo com relação ao apelo a outra liderança neopopulista.

Apesar de identificarem diferenças no tipo de mídia existentes, especialmente devido ao modelo noticioso que cada uma persegue, fica claro no estudo que a variável de maior impacto no modelo analítico proposto Mazzoleni et al. é o tipo de relação estabelecida entre o sistema de mídia e o sistema político. Isto é, uma relação que pode variar de sacerdotal à hostilidade e, em contraposição, de uma defesa efusiva do status quo a uma maior abertura aos argumentos dos líderes neopopulistas. Esse é o ponto que, na visão dos autores, afeta significativamente o processo de produção noticiosa.

\section{Considerações finais}

Por ser um modelo comparativo, The Media and Neo-Populism apresenta, a nosso ver, fragilidades comuns nesse tipo de análise, que busca apontar padrões segundo similitudes observadas nas diferentes democracias. Os autores reconhecem essa dificuldade, mas aqui gostaríamos de pontuar algumas. A primeira dela é saber por que estratégias para furar o bloqueio noticioso da mídia, a midiagenia, frases de efeito e a emocionalidade nas declarações públicas seriam características do neopopulismo, quando observamos esses mesmos comportamentos nos diferentes grupos políticos e lideranças sem que sejam classificados necessariamente como neopopulistas?

Esse ponto aproxima-se do argumento de fundo apresentado por Waisbord no livro, segundo o qual o populismo midiático é visto como variável independente para explicar o populismo político. Longe de resolver, essa análise problematiza mais a questão, porque entende o fenômeno do neopopulismo contemporâneo segundo a lógica da mídia de massa, que acabou sendo apropriada pela política e seus agentes.

Nesses termos, o populismo teria uma conotação mais próxima do sentido de popularidade e reconhecimento público, objetivos comuns na miríade de estratégias adotadas pelos atores políticos nas democracias de massa. Definitivamente, rejeitar essa proposição nos levaria a aceitar o argumento segundo o qual a política é um campo destinado ao confinamento, destinada a discussões etéreas e sem correspondência com a vida mundana.

Um segundo ponto do estudo que poderíamos também citar é a questão da concentração da mídia de massa, especialmente quando observarmos o cenário latino-americano. Se há uma divisão no comportamento da mídia de elite e mídia tabloide, como sugerem os autores, esses dois grupos só tenderiam a adotar uma visão unificada 
da política a partir de mudanças no tipo de relação entre sistema de mídia e sistema político.

O grau de concentração do controle dos meios de comunicação no cenário latino-americano, contudo, enfraquece esse argumento, porque não há razão para um mesmo grupo empresarial adotar enquadramentos distintos da política, segundo o tipo de veículo que controle, bem como não há razão aparente para que adotem igualmente um grau maior ou menor de abertura aos apelos dos grupos populistas, segundo o tipo de veículo (de elite ou tabloide). E por que não há razão? Pelos mesmos argumentos apresentados no livro, segundo os quais os grupos de mídia são movidos também por interesses políticos, que afetam a maneira através da qual enquadram a cena política. Esse é um tema que mereceria, certamente, uma maior discussão. 


\section{Referências}

LACLAU, Ernesto. La razón populista. Buenos Aires: Fondo de Cultura Económica, 2005.

COUTINHO, Marcelo. Movimentos de Mudança Política na América Latina do Sul Contemporâneo. Revista de Sociologia e Política. n. 27, Curitiba: novembrode 2006.

RINCÓN, Omar; MAGRINI, Ana Lúcia. Meios, Poder e Democracia na América Latina - de celebridades políticas, poderes midiáticos e democracia de simulação. In: SORJ, Bernardo (Org.). Poder político e meios de comunicação. São Paulo: Paz e Terra, 2010.

COMPOIITI CA

ASSOCIACAOO BRASILEIRA

DE PESQUISADORES EM

COMUNICACÁO E POLITICA

Presidente: Alessandra Aldé (UERJ)

Vice-Presidente: Luis Felipe Miguel (UnB)

Secretário Executivo: Francisco Jamil Marques (UFC)

Editora-Chefe:

Alessandra Aldé (UERJ)

Editores Executivos:

Edna Miola (UFS) e Viktor Chagas (UFF)

Editores Assistentes:

Eleonora Magalhães (UFF) e Fernanda Sanglard (UERJ)

Revisor: Pedro Sangirardi (UERJ)
A Revista Compolítica é uma revista eletrônica da Associação Brasileira de

Pesquisadores em Comunicação e Política. Com periodicidade semestral, sua proposta é difundir a produção acadêmica relacionada às interfaces desses campos de estudo.

Ao citar este artigo, utilize a seguinte referência bibliográfica

VASCONCELOS, Fábio. A mídia e o neo-populismo. In: Revista Compolítica, n. 3, vol. 2, ed. julho-dezembro, ano 2013. Rio de Janeiro: Compolítica, 2013. 
